Revista Iberoamericana. Vol. LXIII, núms. 178-179, Enero-Junio 1997; 149-171

\title{
EL PERIÓDICO ÁLBUM DE SEÑORITAS DE JUANA MANSO (1854): UNA VOZ DOMÉSTICA EN LA FUNDACIÓN DE UNA NACIÓN
}

\author{
POR \\ Lelia Area \\ Universidad Nacional de Rosario, Argentina
}

Uno puede juzgar el grado de civilización de una nación a través de la posición social de sus mujeres.

D. F. Sarmiento

La Manso, a quien apenas conocí fue el único hombre en tres o cuatro millones de habitantes en Chile y la Argentina que comprendiese mi obra de educación ...

D. F. Sarmiento (OC., vol. 49, 294) (s/m.)

INTRODUCCIÓN

Las dos citas de Sarmiento que encabezan este trabajo han sido privilegiadas con la aviesa intención de dibujar los bordes del paradigma de contradicciones que caracterizó el mapa cultural en el que Juana Paula Manso de Noronha (1818-1875) instala su proyecto de publicar el periódico Álbum de Señoritas. Periódico de Literatura, Modas, Bellas Artes y Teatros en los inicios del año 1854. En este sentido, entiendo por mapa a esa "seria" ficción que representa un paisaje intelectual particular desde un, no menos, particular punto de vista. Situada Manso en el Buenos Aires post-Caseros y dando con ello fin a la proscripción que protagonizara junto a su familia durante el rosismo, con escasos recursos, separada de su marido y teniendo a cargo a sus dos hijas pequeñas su tarea consistirá en llevar a cabo la edición del Álbum.

Esta propuesta tenía como antecedente el OJornal das Senhoras. Modas, Litteratura, Bellas Artes, Theatros e Critica (1852-1854), publicación que la contó como redactora durante los primeros seis meses de esa revista cultural en la ciudad de Río de Janeiro donde vivió la última etapa de su exilio, casada aún con el violinista portugués Fernando Sáa de Noronha. Una vez en la Argentina destinará a sus compatriotas mujeres, el semanario Álbum de Señoritas el que aparece, no obstante, durante tan sólo las ocho primeras semanas del año 1854, período suficiente para demostrar a esa incansable mujer que su empresa había fracasado al perder todos sus suscriptores como reacción a los tonos y temas que pusiese en escena. Su proyecto de reforma en el Buenos Aires de 1854 perseguía el objetivo de actualizar el campo de conocimiento de las mujeres rioplatenses al mismo tiempo que pretendía lograr un modo de susbsitencia a través de la venta del periódico. 
Como uno de los tantos emblemas político-literarios que Sarmiento supiera acuñar, es mi intención hacer jugar, en clave oximorónica ${ }^{1}$ - si se me permite utilizar un neologismo un tanto salvaje-, los acápites mencionados con el objeto de exponer la controvertida escena pública que tanto periodista como periódico revelan. En este sentido no deja de ser altamente llamativo que, cuando el escritor sanjuanino - décadas más tarde- elogia el compromiso intelectual de la Manso sienta que deba modalizarlo con un cambio genérico, con el solo fin de poder dar con el tono que ella supo desatar en su época. De este modo, La Manso fue el único hombre que ... encarnó las contradicciones irreconciliables de esta doble pertenencia genérica pagando, en una difícil trayectoria de obstáculos, los costos que una subversión de tal tipo implica. ${ }^{2}$

Que después de una ausencia de veinte años, al volver a mi país natal encuentre lo que iria á conocer por vez primera.

El lar Patrio! ese bienestar que solo conozco por las descripciones de Lamartine, por los cantos del Child Harold de Byron .... si así no fuese ..... si en vez de simpatias me volviesen indiferencia, si en vez de hermanos hallase enemigos, ¿qué haria?

Alzar el bordon del peregrino e ir á buscar una Patria en alguna parte del mundo, donde la inteligencia de la muger no sea un delito ("Último día del año y año nuevo" en Álbum de Señoritas 1 (1/1/ 1854) 2).

Como hemos expuesto más arriba, el diseño y configuración de cartografias imaginarias ponen en escena espacios culturales donde modalidades discursivas abren (y se abren a) una multiplicidad de recorridos genéricos al mismo tiempo que permiten atravesar los modos de decir de una época. Así, la noción de espacios cartográficos siempre implica una específica topografía epistémica: un paisaje, una forma de conocer o de decir. ${ }^{3}$ En este sentido, me interesa hacer jugar aquí el periódico Álbum de Señoritas de Juana Manso como un mapa de los modos de decir - los que indiscutiblemente ponen en funcionamiento tanto los modos de narrar cuanto los modos de leer- de una de las más controvertidas mujeres argentinas del siglo XIX.

1 Oxímoron: figura retórica que expone sintácticamente la relación significante de dos antónimos.

${ }^{2}$ Lea Fletcher también dibuja el paradigma de la controversia que encarnara la Manso cuando afirma que: "The women writers are there: some, like Gorriti and Mansilla, are just below the surface of patriarchal waters. Others, like the "combatted and combative" Manso, are in deeper waters and hostile to the search. Argentine literary history has been hostile to Manso because she did not observe the codes for women's behavior and discourse, because she spoke outright against injustices. Although she directed the greater part of her energies to women readers, they, along with the men, consistently repudiated her. Aggressively ahead of the oppresive times she lived in, Manso was the most lucid, determined, and selfless of all in her attempts to alter discourse and action" (103).

${ }^{3}$ Véase Derek Gregory. 
Es precisamente en ese siglo que la contribución femenina a la cultura impresa se ve significativamente potenciada por las revistas literarias y los periódicos, una forma sugestiva para las mujeres de entrar en la res publica y brindar una voz propia a la nación. A través de la vía de los periódicos culturales, las mujeres se comprometen en la discusión nacional al mismo tiempo que producen un lenguaje propio para poder ingresar en ese debate. ${ }^{4}$ Estas publicaciones tenían por objeto considerar no sólo las responsabilidades domésticas sino que también revisaban conceptos sobre la belleza femenina y patriotismo. En busca de un nuevo discurso sobre las mujeres que pudiese compensar la atención puesta en la moda, estas revistas femeninas dirigen especialmente su atención a la educación formal. La verdadera conquista de las diferencias físicas, que separaban a las mujeres de los hombres, afirman, debía lograrse a través de la instrucción y el desarrollo moral. En este contexto, la propuesta de Juana Manso de Noronha fue particularmente abarcadora ya que pretendió realizar un cambio revolucionario tanto en las esfera pública como en la privada; sus blancos fueron el autoritarismo de la religión y la familia y la injusticia social de la esclavitud y el racismo.

Cuando Juana Manso, apenas levantado el sitio de la ciudad llegó al Buenos Aires post-Caseros, la sociedad porteña no la recibió con entusiasmo sino que por el contrario tuvo que enfrentarse a un ambiente que le fue abiertamente desfavorable. Sin embargo, como hemos afirmado más arriba, su objetivo era claro: introducirse en el mundo de la prensa, ejercer el periodismo como modo de vida en el marco de las necesidades de su casa - las propias y las de sus dos hijas-y sostener el espacio familiar, dado que había sido abandonada por su marido durante la última etapa del exilio en Brasil. En un primer momento, buscó empleo en periódicos de tendencia liberal sin éxito a pesar de haber tenido como antecedente y experiencia la exitosa revista semanal $O$ Jornal das Senhoras de Río de Janeiro. No obstante los contratiempos y el escaso dinero que aún poseía, llevó a cabo la riesgosa empresa de fundar el Álbum de Señoritas, Periódico de Literatura, Modas, Bellas Artes y Teatros cuya primera entrega apareció en Buenos Aires el $1^{\circ}$ de enero de 1854.

El proyecto de Manso explicitado desde ese primer número aparece jugando un juego doble a través del cual podemos observar cómo la palabra panfletaria se esfuerza por "aparecer" como domésticamente periodística.

... quiero, y he de probar que la inteligencia de la muger, lejos de ser un absurdo, ó un defecto, un crímen, ó un desatino, es su mejor adorno, es la verdadera fuente de su virtud y de la felicidad doméstica porque Dios no es contradictorio en sus obras, y cuando formó el alma humana, no le dió sexo - La hizo igual en su escencia, y la adornó de facultades idénticas - Si la aplicacion de unas y de otras facultades difiere, eso no abona para que la muger sea condenada, al embrutecimiento, en cuanto que el hombre es dueño de ilustrar y engrandecer su inteligencia; desproporcion fatal que solo contribuye á la infelicidad de ambos y á alejar mas y mas nuestro porvenir. Y no se crea que la familia

\footnotetext{
4 "Nuestro lenguaje refleja una cultura sexista, una cultura patriarcal en la que el hombre desempeña el papel principal y la mujer el subordinado. Esto justifica la asociación del 'sexo débil' al mundo infantil, a la esfera doméstica, a la fragilidad, al sentimentalismo y a tantas otras cosas". Para mayor tratamiento del tema, véase López García y Morant.
} 
no es de un gran peso en la balanza de los pueblos, ni que la desmoralizacion y el atraso parcial de los individuos no influye en bien ó en mal de la sociedad colectiva ("La Redaccion" en Álbum de Señoritas 1 (1/1/1854) 1).

No olvidemos que todo texto es, en realidad, un escenario armado por el autor para establecer su propuesta en el campo de un diálogo imaginario con el lector, al que ubica como un cómplice, una autoridad, un objetador o un adversario. Es que ese autor juega a instalarse - siempre - como un lector social del rumor de discursos fechados, mientras se vuelve - al mismo tiempo- en un escritor de silencios pautados por la época. En este sentido, el Álbum de Señoritas puede ser pensado como un verdadero mapa desplegado a través del cual es posible leer los temas y problemas que interesaban a la proscripta recientemente vuelta a su patria. A través de sus páginas la Manso comentará las leyes en Estados Unidos, discutirá la importancia de los nuevos aporte tecnológicos, atacará la base de la iglesia católica, ${ }^{5}$ insistiendo en la necesidad de la libertad de palabra, ${ }^{6}$ escenas discursivas que apuntan —desde todos sus flancos- a la soledad que protagonizaría su proyecto.

\footnotetext{
${ }^{5}$ Son tantos y tan variados los temas a través de los cuales el Álbum, revulsivamente, desarticula el statu quo que resulta difícil atravesarlos dado que los mismos estallan en (y hacen estallar) -en sentido literal y metafórico - los lugares imaginarios y simbólicos del saber común. En "Libertad de Conciencia" nota aparecida en la séptima entrega de fecha $12 / 02 / 1854$, la cronista del semanario se atreve a "tocar" uno de los temas más ríspidos en la historia no sólo de la emergente nación, sino en la mucho más abarcadora de la tradición occidental. Dice Manso: "Hace días que una polémica religiosa entre católicos que gimen y protestantes que dogmatizan (según dicen), ha aparecido en los periódicos de Buenos Ayres, haciendo sobre los espíritus ilustrados en la materia, el mismo efecto que haría un muerto que saliese de su sepultura y pasease su desnudo esqueleto por entre los vivos. ¡Qué! despues de veinte años de una dictadura de hierro; despues de veinte años de una inquisición política, estariamos condenados á ver la Iglesia Católica desarrollar su estandarte negro sembrando de huesos y de cráneos? /.../iCómo! señores católicos, pretendeis resuscitar el fantasma pavoroso de la heregia! ¿Creeis que todos los tiempos son unos? ... Ignorais que hay en Buenos Ayres plumas bastante valerosas y almas asaz firmes, que están prontas á pulverizar vuestros sofismas? /.../¿Los protestantes dogmatizan? ¿Y que mal hay en eso? ¿No es la palabra de Cristo la que predican? ¿Entonces por qué los llamais de hereges? .... ¡Cuando este desgraciado pais tiene tanta necesidad de la palabra de paz, venis vosotros á lanzar el grito de guerra y el anatema! ¡Venis gritando quien vive, dando alarma al Gobierno, á la autoridad eclesiástica y á las familias! .... Es nuestra conviccion íntima, que todo aquel que no sea consecuente con sus principios, hará siempre las cosas á medias. La libertad una vez proclamada, no tiene otros límites que los mismos que tan sabiamente le ha opuesto la propia naturaleza de las cosas! ¡Nunca ha sido el esceso de la libertad el que ha causado los males de los pueblos, por eso, un Gobierno que proclame entre otras libertades la libertad de conciencia, nunca debe declamar una religion del Estado para no cometer el absurdo y no estár en contradiccion consigo mismo! Aquí no hay término medio. Es necesario optar entre una cosa ó la otra!/.../ (Álbum de Señoritas 7 [12/2/1854] 55. El subrayado pertenece al texto original). La "provocación" de la cronista obtendrá a lo largo de su vida duras y violentas respuestas. No puede asombrarnos entonces que como recuerda Liliana Zuccotti, tras su muerte el 24 de abril de 1875, el cadáver de Juana Manso haya permanecido insepulto por dos días a causa de que se le negara un lugar en los cementerios de la Chacarita y de Recoleta. "Como último gesto - dice Zuccotti- la Manso, Doña Juanita, Juana la loca se ha negado a recibir los últimos sacramentos de manos de un
} 
Me interesa ubicar en este momento una pregunta que pueda abrirse como interrogante en el estudio del periódico Álbum de Señoritas, en la medida en que considero que éste se presenta como el emblema del proyecto "doméstico" a través del que Juana Manso imagina una nación. Me refiero, en este contexto, a preguntarnos cuál sería la convención literaria esencial del periódico como modalidad genérica y discursiva. ${ }^{7}$ La respuesta podría ser ubicada en la idea de que todo periódico - como propone Benedict Anderson-genera la ficción de imaginar conexiones entre hechos que se darían en un "aquí y ahora" figurados narrativamente. Estos lazos imaginados derivarían de dos fuentes relacionadas oblicuamente: la primera es simplemente la coincidencia de calendario; la fecha en el encabezado del periódico proveería de la esencial conexión entre los "hechos"-el estable reloj interno de un tiempo vacío, homogéneo. Dentro del tiempo, es "el mundo" el que avanza tenaz y narrativamente, por lo que el formato novelístico del periódico aseguraría la reaparición de los personajes. Por otra parte, la segunda fuente de un lazo imaginado residiría en la relación que existe entre el periódico, como una forma de libro, y el mercado (Anderson). ${ }^{8}$

En este contexto, los periódicos hispanoamericanos que surgieron hacia fines del siglo XVIII se escribieron con plena conciencia de sus provincianos editores y escritores acerca de la existencia de mundos semejantes al suyo. Los lectores de periódico de la ciudad de Buenos Aires, Santiago o Montevideo, aunque no leyeran los periódicos de las otras ciudades, estaban muy conscientes de su existencia. Así se explica, afirma Anderson, la conocida duplicidad del temprano nacionalismo hispanoamericano, su alternancia de gran alcance y su localismo particularista.

sacerdote católico. Convertida hacía ya varios años al anglicanismo, rechaza la advertencia que le hace horas antes de morir una comitiva enviada para 'convertirla'. Recién en 1915, cuando la escuela pública se imponga como el instrumento adecuado para nacionalizar a las masas inmigrantes, los restos de Juana Manso son trasladados al panteón de maestras de la Chacarita" (en Fletcher, Mujer y cultura 96).

${ }^{6}$ Véase Masiello, La mujer y el espacio 14.

${ }^{7}$ Dice Anderson al respecto: "Si echamos una mirada a la primera página de un ejemplar como es The New York Times, podríamos encontrar allí historias sobre los disidentes soviéticos, las hambrunas en Mali, un tremendo asesinato, un golpe en Irak, el descubrimiento de un raro fósil en Zimbabwe, y un discurso de Mitterand. ¿Por qué están todos estos acontecimientos yuxtapuestos? ¿Qué los conecta a todos entre sí? No un simple capricho. No obstante obviamente la mayoría de ellos sucedieron independientemente, sin que los actores estuviesen al tanto uno de otros cuando las cosas sucedian. La arbitrariedad de su inclusión y yuxtaposición (una edición de último momento podría substituir un triunfo de baseball por Miterrand) muestra que las relaciones entre ellos son imaginadas" (Anderson).

${ }^{8}$ El periódico aparecería ante los ojos de sus lectores como una "forma extrema" del libro, un libro vendido en una escala colosal, pero de efímera popularidad. La obsolescencia del periódico en la mañana misma de su edición crea la ceremonia de consumir (imaginariamente) el periódico-comoficción. La significación de esta ceremonia masiva es paradójica ya que la misma se lleva a cabo en silenciosa privacidad al mismo tiempo que cada lector es altamente consciente de que esa ceremonia que él actualiza es repetida simultáneamente por miles de otros lectores de cuyas existencia él confia, aunque de cuya identidad no posee la más mínima noción. Es más, esta ceremonia es repetida diariamente $o$ a intervalos a través del calendario. 
Por otra parte, en el siglo XIX, el surgimiento y evolución de la prensa significó un sensible desarrollo para la literatura. El lenguaje interrumpido, discontinuo, de la conversación encontró en la simultaneidad y el fragmentarismo periodístico una forma privilegiada para luego desplazarse - también como "forma"- a la literatura. Aunque sin duda la entrega semanal o mensual del material escrito debe haber causado dificultades a los escritores, en especial debido a la tensión y a la urgencia en la elaboración del material creativo, también hay que reconocer que esta modalidad de escritura tenía sus ventajas: la publicación periodística permitió una difusión de la obra hasta entonces pensada como imposible; como consecuencia de la urgencia por entregar el material escrito, los escritores tuvieron que acostumbrarse a hacer más ágil la labor, a combinar las acciones de tal manera que la atención de los lectores pudiera mantenerse en suspenso hasta la siguiente entrega. Es decir que los escritores debieron alcanzar un gran dominio técnico.

El género folletín ${ }^{9}$ nace, entonces, a fines del siglo pasado cuando el periodismo, con el fin de mantener y aumentar suscriptores, se aparta de la pura función noticioso-crítica que le era propia e incluye la ficción narrativa en sus páginas. Este tipo de literatura muestra el funcionamiento de "máquinas" montadas para retener la fidelidad consumidora del lector, funcionamiento que por imposición de los mecanismos de la prensa abarcaba centenares de páginas y decenas de tomos. La "modalidad folletinesca" tiene por característica poner en escena frecuentes cortes en la narración los que provocan y prolongan el suspenso, el proceso de desplazamiento de un personaje principal y el paralelo ascenso de un protagonista secundario, las incongruencias y los paralogismos, las resurrecciones impuestas por las presiones del público, los juegos con las apariencias de las cosas, los puentes tendidos hacia el lector y las complicidades del narrador omnisciente.

Hay elementos que desde el comienzo aseguraron al folletín el éxito de público que siempre obtuvo, entre ellos se pueden destacar: la fragmentación y el suspenso. Las novelas de folletín utilizaron el suspenso como el procedimiento privilegiado para mantener en vilo la atención de los lectores entre un número y otro (que podía aparecer cada semana o cada quince días). El dejar abierta la narración, con diferentes posibilidades de continuación, reforzaba el contacto con el lector y posibilitaba una especie de juego de ajedrez entre autor y lectores, que tenía por objeto lograr un grado extremo de tensión.

En este contexto discursivo, es decir, el del género periodístico como puesta en escena de una comunidad imaginada y el del folletín como modo narrativo explícito e implícito de un relato fragmentario, analizaré la quinta entrega del Álbum de Señoritas fechada el 29 de enero de 1854. Dicho análisis me permitirá, a modo de síntesis emblemática, y desde un ángulo-otro de lectura, posicionarme en un punto de vista oblicuo y atravesar el proyecto periodístico de Juana Manso tanto temática como problemáticamente al mismo tiempo que me permitirá evaluar la imagen de nación que el periódico sostuviera.

\footnotetext{
${ }^{9}$ Jorge Rivera sostiene que la novela de folletín ocupó con fuerza avasalladora la imaginación de los lectores del siglo XIX. Su universo, construido a base de falsas identidades, reconocimientos imprevisibles, sustituciones misteriosas y asedios a la inocencia reivindicada, hizo resurgir en plena revolución industrial, curiosamente amalgamados con elementos de la novela burguesa realista, las fantasías más antiguas de la imaginación popular.
} 
De esta forma, no resulta en modo alguno ocioso reiterar aquí el hecho de que desde el punto de vista publicitario- “ "Álbum de Señoritas amplía considerablemente la gama de temas de las revistas anteriores ya que habla del progreso argentino, la ciencia y el oficio de escritor/a, vistos exclusivamente desde la perspectiva de la mujer" (Masiello). Asimismo, es fácil notar que cuando Juana Manso se dirige a las mujeres de su época -a quienes con insistencia denomina "compatriotas" - instala su propuesta a través de la potenciación de dos polos también temáticos y problemáticos; polos a los que les otorgara carácter de etapas para la consecución de su proyecto. Ellos son:

1.- la emancipación moral e intelectual de las mujeres, ${ }^{10}$

2. - la integración de esas mujeres así emancipadas en el proyecto de renovar el país una vez que se hubiese logrado corregir las modalidades imperantes en la familia y en el Estado.

En este sentido, la elección de la quinta entrega como objeto de análisis tiene, a mi entender, varias razones "operativas" que desearía poner de manifiesto:

a) considero que este número de la revista juega como una verdadera bisagra en el proyecto periodístico de la Manso en función de que "objetivamente" podemos ubicarlo en la mitad de esta empresa y "leer" - tanto en sentido literal cuanto en el metafórico- la evaluación que realiza de la misma, ${ }^{11}$

b) al mismo tiempo, dicha entrega "cierra" el primer mes de la publicación y (nos) muestra los temas y tonos que la cronista había privilegiado hasta entonces en su periódico;

c) por otra parte, en su número cinco, el Álbum despliega una escena discursiva donde los tonos de la esperanza y el desencanto juegan un rol protagónico nunca repetido a lo largo de las entregas precedentes y posteriores.

Para finalizar, expondré aquí el diseño del número cinco de Álbum de Señoritas para así, a continuación, poner en funcionamiento los modos de leer que configuran los modos de narrar una imagen de nación en conflicto:

Quinto número: (Enero 29 de 1854)

*Ilustración de la Muger. Filosofía. Psicología-Estudio del Alma Humana.

*La Homeopathia. Medicina Casera.

*Viages del Conde de Castelnau por El Interior de América. Entrada al Perú, Puno, lago de Chucuito, Arequipa, Islay.

*Al Cruzar la Equinoccial.

* La familia del comendador. Novela Original por Juana P. Manso de Noronha (Nuera y Suegra)

*Las Misiones.

*Coincidencia Singular.

*Al Señor G. de la "Tribuna".

*A Nuestras Subscriptoras. Juana P. Manso de Noronha.

*Modas -Máximas Morales.

\footnotetext{
${ }^{10}$ Manso escribía sobre la necesidad de educación popular, libertad del dogma católico, instrucción filosófica, psicología, homeopatía, arte.

11 Véase “A Nuestras Subscriptoras” en Álbum de Señoritas 5 (29/1/1854) 40.
} 
Si nos viéramos en la necesidad de apelar a una calificación generalizadora para evaluar la actitud asumida por Juana Manso - en lo que a publicar el Álbum de Señoritas se refiere-, ésta sería la de ejemplar. En este contexto, el plan general del periódico, reiterado a lo largo de sus ocho números, permite dibujar algunas zonas donde ese modo "ejemplar" - polémicamente ejemplar, sería mejor expresarlo- de la periodista trama su recorrido de intereses; zonas éstas que pueden ser clasificadas de la siguiente manera: educación para la mujer, información sobre temas no-convencionales (mesas giratorias, homeopatía), viajes, relatos auto-bio-gráficos, "La familia del comendador"12 (novela en folletín), modas, crítica teatral (con especial acento en el género operístico) miscelánea (poemas, anécdotas, máximas). A través de ellas, podemos recorrer los temas que la cronista consideraba de interés para las lectoras argentinas de mediados de siglo XIX; sin embargo no podemos dejar de notar que la mencionada "ejemplaridad" debe haber resultado, en más de una ocasión, demasiado aleccionadora para aquéllas. En este sentido, es fácil percibir una escena discursiva en la que Manso aparece "confundiendo" (o tal vez podríamos decir mejor: co-fundiendo) tanto los temas como los tonos de su época al pretender hacer con y del Álbum un gran espacio escolar en el cual podemos verla plantarse como única enseñante.

Es precisamente en este contexto que desearíamos arriesgar una conclusión (parcial) a lo expuesto hasta el momento: desde su Álbum de Señoritas, ella (nos) propone un diseño de nación entendido como gran escena áulica donde la comunidad es imaginada en el grado cero - tabula rasa - de la historia de un estado que aspira a ser moderno. De esta forma, el gesto de fundación se piensa a partir de una ejemplar "construcción del conocimiento" a través de la cual las mujeres debían tomar un rol protagónico tras haber aprendido a asumir su lugar en la nueva escena política que surgiera después de la caída de Rosas.

En función de lo planteado anteriormente podemos, entonces, observar cómo la quinta entrega se abre con la nota "Psicología-Estudios del Alma Humana" en el marco de la sección "Ilustracion de la Muger" donde la cronista ${ }^{13}$ intenta con innegable dificultad

\footnotetext{
${ }^{12}$ Texto escurridizo, si los hay, La familia del comendador tiene el privilegio de aparecer como la presencia de una ausencia en cuanto biblioteca y archivo uno intenta consultar. Dice, al respecto, Lea Fletcher que "aunque la designación de una u otra obra como la primera novela argentina es, en última instancia, una cuestión de criterio, La familia del Comendador se puede considerar la primera novela escrita por una mujer - y aquí me falla el idioma porque quiero decir que es la primera novela escrita por un varón también - que se publicó en el país. Sin embargo, ser la primera no es el tema, sino ser el objeto de amnesia generalizada, como lo fue esta novela y su autora" (Fletcher, "Juana Manso ..." 109).

${ }^{13}$ Desde el primer número del Álbum, podemos notar cómo Juana Manso muestra "estar consciente" de los riesgos que implicaba su tarea de cronista en lo referente a la relación que siempre ha existido entre una acertada elección de los temas (y de tonos, podríamos agregar) y la captación de un público lector consecuente. En la nota "Crónica semanal" de fecha 1/1/1854 dice: "De todos mis compromisos, es éste el que considero mas sério. El oficio de cronista tiene mil peligros, el mas eminente, hacer bostezar los lectores. ¡Vaya una idea consoladora y lisonjera! .... Despues si dice una lo que piensa, malo, y si no lo dice peor ..." ("Crónica semanal" en Álbum de Señoritas, (1/1/ 1854) 7).
} 
"imponer" un conocimiento a sus lectoras: los fenómenos del alma como objeto de estudio de la psicología. Desde una "laicidad" altamente significativa para la época - la que, por ello mismo, debe haber resultado no menos "amenazante" en la pluma de una mujerJuana Manso propone considerar la existencia personal como base y legítimo punto de partida de la ciencia. Dirá entonces que:

Yo pienso, luego existo: el yo, piensa, siente y obra, y quien le dá la certeza de que piensa, siente y obra, es la conciencia.

El testimonio de la conciencia es irrecusable. El juicio puede extraviarse, la conciencia jamás, porque sentimos como sentimos y queremos como queremos, y no hay argumentos que valgan á persuadirnos de lo contrario, porque contra esos hechos íntimos y arcanos que pasan en el fondo de nosotros mismos, nada se puede decir ("Ilustración de la Muger. Filosofía. Psicología - Estudio del Alma Humana”, Álbum de Señoritas 5, 33, subrayado original).

A continuación podremos leer un artículo sobre "Medicina casera" en el marco de un tema para-científico: La homeopathia donde nos enfrentamos a la apuesta discursiva que realiza la periodista para llegar a descorrer los velos que el "saber común" cristalizara con respecto al tema. Así, declarará sin embages que el "error que generalmente condena la homeopathia sin conocerla, nos induce á dar á nuestras lectoras una idea verdadera de lo que viene á ser la homepathia". Apelando a una cita de autoridad - "oíd lo que dice Jahrr, la mejor autoridad á este respecto" - interesa a sus lectoras a informarse sobre la Naturaleza y forma de los remedios homeopáthicos con vistas a desautorizar los numerosos prejuicios que invalidaran este saber.

"Viajes del Conde de Castelnau por el interior de America. Entrada al Perú, Puno, lago de Chucuito, Arequipa, Islay" es el título que encabeza la siguiente nota, la que debe ser leída en el marco de la serie de notas similares iniciadas en el primer número. Inserta en la trama genérica narración de viajes ${ }^{14}$ este artículo escenifica una "mirada" hacia el interior de América de la mano de un ignoto Conde de Castelnau ${ }^{15}$ quien ofrece, en este número,

\footnotetext{
${ }^{14}$ En "Viajeros intertextuales", Isabel Stratta señala que la "narración de viajes es un género conocido desde la antigüedad, pero tuvo su apogeo entre fines del siglo XVIII y principios del siglo XIX, cuando la oferta de relatos sobre las expediciones confluye con la existencia de un amplio circuito de divulgación pública, sobre todo en Inglaterra - donde los diarios y actas del Royal Geographic Society contaban con la entusiasta recepción de todo tipo de lectores-, y también en Francia. Es la época [dice Stratta] en que se divulgan las narraciones de las 'vueltas al mundo' -Bougainville, Cook, Byron el almirante- y se publican una cantidad de recopilaciones, compendios, historias generales del viaje y otros volúmenes antológicos que hablan de la necesidad de ordenar y discriminar un corpus ya vasto en las bibliotecas de occidente" (Isabel Stratta, "Viajeros intertextuales" en Area y Moraña 106).

${ }^{15}$ No podríamos asegurar si la firma del viajero es "auténtica" o apócrifa, sí tan sólo señalar que el Castelnau de las primeras seis entregas se volverá el Castelnaux de la séptima y última participación en el Álbum. Probablemente Juana Manso haya accedido a esta narración de viajes durante la época en que viviera en Brasil dado que tema y autor no son una referencia conocida en la bibliografía que trabaja este tipo de narraciones.
} 
información sobre la ciudad y el departamento de Puno. Aquí también podemos percibir que el tono puesto en escena evoca mucho más los acentos de un manual escolar que el de las narraciones de viajes tradicionales dado que la nota se articula en el marco de una sucesión de datos sobre cantidad de habitantes, ${ }^{16}$ tipo de población y producción (tipo de animales, producción agrícola) sin marcas explícitas de la subjetividad del viajero. ${ }^{17}$ Probablemente, en la elección de esta narración, Manso haya pretendido alejarse de la exaltación de ese tipo de "subjetividad", el que había dado como resultado los, a menudo, caóticos relatos de navegantes y aventureros y por ello haya apelado a uno cuyas marcas ponían el acento en el -aleccionador- lenguaje proveniente de las ciencias naturales. No quedan dudas de que detrás de la "mirada" científica del viajero está el ojo atento de la periodista-docente pendiente de su superobjetivo: ${ }^{18}$ educar a las mujeres de su patria, decidiendo sobre qué, cómo y hasta dónde deben de informarse. En este sentido Manso es explícita por lo que finalizada la nota del Conde de Castelnau podemos leer lo siguiente:

Sigue un mapa de las minas hoy en trabajo, su extraccion de mineral, azogue, sus gastos \&c. \&c. Esta noticia estadística, como es probable que no agrade á mis lectoras, la suprimiremos, tomando el hilo de la historia, mas adelante, en el próximo número. ("Viajes ..." en Álbum de Señoritas 5 (29/1/1854) 34, subrayado mío).

\footnotetext{
${ }^{16}$ Sólo a título de ejemplo de lo planteado al respecto, considero interesante transcribir aquí un fragmento de la nota mencionada: "La ciudad de Puno debe su fundacion á la vecindad de numerosas minas cuya explotacion era en un tiempo muy floreciente. Hoy la mayor parte de esas minas están abandonadas, y sus trabajos han sido reemplazados por los de la agricultura, de un resultado mucho más seguro; es verdad que la ciudad ha perdido de su antigua prosperidad; con todo, Puno es una linda población de seis mil habitantes; sus calles principales son bien delineadas y empedradas con gusto; posee un colegio y un hospital bien dotados" ("Viajes del Conde de Castelnau por el Interior de America. Entrada al Perú, Puno, lago de Chucuito, Arequipa, Islay" en Álbum de Señoritas, 5 (29/1/1854) 34).

${ }^{17}$ Salvo un lacónico: "Alli vimos por primera vez la carne de las Llamas ..." (Álbum de Señoritas, 5 (29/1/1854) 34 .

${ }^{18} \mathrm{Me}$ interesa, en este momento, pedir en préstamo a la dramaturgia la categoría de superobjetivo ya que la considero particularmente "operativa" para mi planteo. Así: superobjetivo: es una traducción literal del ruso. También ha sido adaptado como columna vertebral (E. Kazan, USA) o acción fundamental (H. Clurman, USA). Punto de confluencia (tópica) al que conduce un sistema de acciones lógicas montadas en la conducta de un personaje o varios, en términos no tanto actorales como dramatúrgicos. Desde esta concepción constituyó una preocupación técnica de Stanislavski por adecuar el comportamiento ficcional de sus actores al propósito del dramaturgo, a un significado particular entendido como "rector". "Objetivo complejo que resume, desde el punto de vista de la acción, todos los fragmentos y objetivos subalternos de una obra..." “...éste no se encontrará sino después de un largo tiempo"./ "Tema principal..."/ "...en una obra, la corriente total de objetivos individuales menores, todas las ideas imaginativas, sentimientos y acciones del actor convergerán para lograr el super-objetivo del argumento. La unión común debe ser tan fuerte que hasta el pormenor más insignificante, si no está relacionado con el super-objetivo, se destacará como superfluo o equivocado"./ "Propósito básico de la obra... leit motiv" (Stanislavski 263). Véase el artículo "Una polémica sobre dirección” en Jiménez.
} 
No obstante, frente a la cuarta nota nuestra operación de lectura (aparentemente) debe dar un giro de ciento ochenta grados para así poder percibir el cambio de tono que, "Al cruzar la equinoccial", actualiza. Con este objeto, evocamos aquí una de las figuras ${ }^{19}$ discursivas que acuñara alguna vez David Viñas ${ }^{20}$ en su trabajo sobre Lucio V. Mansilla cuando propusiera pensar la metáfora del círculo protagonizado por los gentlemen escritores con un adentro - encarnado por aquellos que sostenían los valores de la genteel traditiony un afuera - asumido por los que quedaban fuera de los márgenes delimitados por el círculo mencionado. A partir de dicha delimitación, Viñas "jugaba" con diversas combinaciones las que, a su vez, con-figuraban espacialmente grados de cercanía o lejanía respecto de la centralidad; ellas eran: el afuera del adentro y el adentro del afuera. Precisamente es la gestualidad de estos dos entrecruzamientos figuráticos la que desearía articular en la lectura de "Al cruzar la equinoccial" ya que si la impronta docente puesta en escena por Juana Manso en las dos primeras notas parecía referencializar una figura de centralidad ejemplar — con límites interiores y exteriores claramente emarcados por el saber y el no-saber-, la modalidad "montada" en esta nota atraviesa esos bordes, confundiendo - y co-fundiendo, como lo planteáramos más arriba- lo privado en lo público. Al apartarse del (público) tono docente para adoptar el (privado) de la confidencia, la periodista atraviesa transversalmente, con movimiento zigzagueante, los bordes de las mencionadas fronteras mientras confia algunos acontecimientos de su vida privada a las lectoras del Álbum.

Desde un ángulo-otro (por lo equidistante) al de la ejemplaridad, la figura de la confidencia ${ }^{21}$ evoca - a veces - el secreto, - siempre - lo privado dado que podría ser pensada como esa escena de lenguaje que, al poner en juego la intimidad, permite a la palabra transitar a media voz. Es precisamente esa tonalidad la que Manso articula en esta nota: la de una media voz a partir de la cual procederá a relatar(nos) las sensaciones que tuviera "una noche de Diciembre de 1848" cuando - junto a su marido e hijas- regresaba al Brasil, por barco, y "la disminución progresiva de la latitud, [les] anunciaba que de un momento al otro [debían] cortar la línea misteriosa que divide en dos los hemisferios del globo terráqueo".

\footnotetext{
${ }^{19} \mathrm{Si}$ bien la pretensión de definir la categoría de figura nos llevaría a atravesar toda la historia de la retórica occidental, nos interesa convocar aquí el modo de percibirla que tiene Roland Barthes cuando plantea que una "figura se funda si al menos alguien puede decir: ' $Q$ Qué cierto es! Reconozco esta escena de lenguaje"' (Barthes).

${ }^{20}$ Texto paradigmático, Literatura argentina y realidad politica, funda - sin lugar a dudas - algunos de los gestos de la mirada crítica de los sesenta en lo que a la lectura de la literatura argentina se refiere, al desacomodar, sin ningún tipo de condescendencia, las tranquilas aguas de los "canónicos panoramas" de la historia de la literatura manejados hasta el momento. El presupuesto de lectura de Viñas es que la literatura íntegra es una gran clave y su necesaria síntesis, la selección de elementos sobre el fondo de su contexto. En este sentido, sus imprescindibles elipsis ponen de manifiesto lo que no se dice articulado con el amplio cociente de alusiones que se implican. Es decir, la cabal comprensión de una literatura si se apoya en lo explícito permanentemente reenvía al contexto, un contexto que aparece como tácito por definición. Véase Viñas, Literatura argentina.

${ }^{21}$ Esta figura la he trabajado en "Martín García Mérou: Confidencias de un Discípulo", inédito.
} 
El tópico narrado será una buena excusa para vehiculizar el tono elegido en función de que una anécdota menor nos permite descubrir, también, a una Manso-otra, protagonista de una escenografia de sentimientos privados:

\begin{abstract}
A bordo era un silencio profundo, ni mas que el ruido de la quilla cortando las aguas, ni mas que la brisa pasando por entre las cuerdas y amarras, que producia como el sonido de una arpa rolia, y la risa inocente de mis chiquitas, agenas todavia á las diferentes escenas del drama de la vida ... despues, hasta esa inocente charla cesó, ellas durmieron, y el silencio reinó mas profundo. El capitan se habia ido á la proa, alli con el anteojo de noche recorria siempre el horizonte. El otro capitan africano pasagero estaba á un lado de la borda, en el tope del mastelero de descubierta un bravo marinero. Nosotros al pié de la puerta de la cámara, conversando en voz baja, palabras de un idioma que no es de este mundo, porque la augusta magestad del espactáculo que teniamos á la vista; aquel Oceano sin límites, aquella luna tan luminosa, aquellos millares de astros que fulguraban, sobre nuestras cabezas, ese reposo y placides de una naturaleza que en solo un minuto podia trocar su faz y sumergirnos para siempre, ese espectáculo pues, dá una gravedad religiosa a los pensamientos, y un colorido singular á las conversaciones, cuando esa proviene de dos corazones poetas, que saben sentir esas bellezas de la naturaleza, que no son para delinearse con los débiles, incorrectos trazos de la pluma ("Al cruzar la equinoccial" en Álbum de Señoritas 5 (29/1/1854) 35, subrayado mío).
\end{abstract}

Así, una lógica (femenina) del afecto aparece configurando una escena de rasgos románticos, guiños, complicidades, es decir, sutilezas. En este marco, memoria y recuerdo se posicionan en un espacio privilegiado, teatralizado, donde naturaleza y cultura se confunden en un murmullo, en un susurro. Vemos, entonces, que la privacidad de esta media voz pareciera como si operara "entre paredes", mientras lo íntimo se muestra potenciando la confianza ${ }^{22}$ que toda confidencia estatuye en el otro, que en este caso es una confianza que Juana Manso deposita en sus eventuales lectoras.

Tras este hiato confidente a través del cual pareciera que la cronista hubiese querido dejar por unos instantes la sonora palabra militante para perder su mirada en el recuerdo y construirla, desde la memoria, en una media voz, la quinta entrega del Álbum de Señoritas

${ }^{22}$ Sólo en otro momento del Álbum Juana Manso reedita esta "confianza". Se trata en una nota miscelánea denominada "Variedades" $\left(n^{\circ} 3,15 / 1 / 1854\right)$; en ellas sus lectoras deben haberse sentido involucradas al verse enfrentadas a un escenario inusualmente confidencial cuando la periodista les participa que: "Alejandro Magarinos y Cervantes, vino un dia á visitarme á San Domingos, parte de la poblacion de Playa Grande, ambos estábamos expatriados. El seguia para España; yo debia casarme en esos dias. ¿Quién puede descifrar el corazon?.... En uno de esos dias inesplicables, en que no se sabe ni siquiera explicar lo que sentimos (...) Era uno de esos dias que yo gusto pasar callada, oyendo no sé el que, y mirando los dombos del cielo....ocupacion poco industrial si se quiere, pero cada cual es como es y no como deberia, ser. (...) Ese dia yo trazaba, asi sin querer, algunas líneas, estaba triste, hé ahí lo que yo escribia (en ese tiempo aun tenia la pretension de hacer versos) (...) Despues de estos versos, dejé correr mis lágrimas en libertad .... Todavia no nos habiamos hablado una palabra. Conversamos entonces largamente-Como hacen yá 9 años de esta escena, tragi-cómica filósofa-poética, mis lectoras no llevarán á mal que pase en silencio el diálogo en prosa y finalize aqui" ("Variedades" en Álbum de Señoritas 3 (15/1/1854) 22-23, subrayado mío). 
enhebra el capítulo (también quinto) "Nuera y Suegra" perteneciente a la novela original (en folletín) La familia del comendador escrita por Juana P. Manso de Noronha. El tema principal de la novela es la injusticia del racismo y la esclavitud; tema que — según Lea Fletcher- instala el siguiente interrogante:

¿por qué creía —e insistía- Manso en que las argentinas, primero en las páginas del Album de Señoritas y después en forma de libro, deberían leer La familia?

La cultura dominante de la Argentina - agrega Fletcher- siempre se vanoglorió de ser un país blanco y la historia nos enseña que se hizo todo lo posible para que así fuera (Fletcher, Mujeres y cultura 111).

En nuestro caso, consideramos que dicho cuestionamiento puede ser fácilmente extendido a todo el periódico en la medida en que se muestra como el proyecto de una comunidad imaginada en discordancia mientras señala una imagen de nación en conflicto. Si bien la lectura de un capítulo en particular nunca puede dar idea de la trayectoria narrativa de un texto, nuestra pretensión, aquí, no reside en llevar adelante su análisis sino, por el contrario, "detectar" el eje problemático de la narración a partir de un golpe de sincronía" que hemos operado en la lectura de la quinta entrega del Álbum de Señoritas. Al atravesarla no podemos sino ratificar el fuerte sentimiento anti-esclavista puesto en juego en el relato lo que nos permite percibir que Juana Manso y su novela estaban indiscutiblemente a la vanguardia de los nuevos aires y los nuevos líderes que tenían en sus manos la reconstrucción nacional. Detengámonos tan sólo en un fragmento de este quinto capítulo para "escuchar" una mirada - valga el oxímoron - a todas luces acerbamente crítica que señala sin concesiones - y a través de la metáfora narrativa que escenifica toda novela — las crueldades de un sistema de relaciones perverso basado en el sometimiento del otro.

${ }^{23}$ A riesgo de estar realizando una reducción un tanto brutal, considero interesante evocar aquí la categoría de "golpe de sincronía" formulada por Marc Angenot quien propone que "la notion de synchronie dont je me réclame est en tout opposée à celle de la linguistique structurale. La synchronie saussurienne est une construction idéale formant un système homéostatique d'unités fonctionnelles. La synchronie dont nous parlons forme une contemporanéité en temps réel. Si nous admettons, dès lors, qu'il existe notamment d'une division réglée des champs et des genres discursives, cette synchronie-là doit faire aussi apparaîttre les points d'accrochage et de conflit, les formations idéologiques émergentes et d'autres récessives, archaïques. Dans les discours social, il y a certes une hégémonie transdiscursive qui tend à homogénéiser les pratiques, à imposer des thématiques communes, à arbitres entre les genres et les secteurs. Il y a aussi du 'bougé', des déstavilisations, des affrontements, plus ou moins superficiels ou bien radicaux. Autrement dit, la contemporanéité des discours sociaux doit être perçue comme una realité complexe et partiellement héterogène, oú s'inscrit l'historie même des discours particulaires, leur relative autonomie, leurs traditions propres et leur rythme d'evolution. En d'autres termes, si la recherche vise à faire ressortir une complémentarité disccursive, une coïnteligibilité des thématiques, des affrontements eux-mêmes ritualisés et, en quelque sorte, fonctionelles, elle doit également et dialectiquement prendre en considération les failles du système, les glissements, les ruptures, les incompatibilités apparues entre formes instituées et formes émergentes" (Angenot). 
Doña Maria das Neves nunca dormia en su cama; vivia el día y la noche reclinada en un inmenso sillon de ruedas, y cuatro esclavas en derredor suyo, no tenian otra ocupacion que la de velar de continuo á las necesidades y comodidad de su señora.

Ya moviéndola del sillon, ya rodando este con esfuerzo á donde aquella ordenaba, ya lavándola, peinándola, haciéndole aire, ó dándola de beber.

En premio de tan improbo trabajo, cuando doña Maria estaba en sus dias de mal humor, las arañaba, las maltrataba y les decia mil improperios.

La comida fué suntuosa, y servida con aquel requinte de delicadeza y buen gusto de una mesa brasilera de buen tono, en que los manjares son siempre escogidos, y en que una multitud de esclavos atentos y vigilantes procuran adivinar el pensamiento de los blancos! ....

¡Míseros! menos felices que los perros, ni aun asi suelen recibir un elogio ó una mirada benévola! ("La familia del comendador: Nuera y Suegra" en Álbum de Señoritas 5 (29/ 1/1854) 36 , subrayado mío).

El fragmento privilegiado más arriba dibuja emblemáticamente el diseño de una sociedad autoritaria y por ende, injusta en la cual los sometidos quedaban reducidos a un estado de naturaleza, pre-social. ¡Gesto aleccionador el de Manso! Aleccionador, además, porque no se detiene tan sólo en este señalamiento —el que podría haber sido considerado hasta previsible para el imaginario de la época - sino que se atreve y —osadamente- da un paso más adelante cuando, algunos tramos después, decide "homologar" implícitamente el estado de esclavitud a la situación de precaria subsidiariedad que debían soportar las mujeres en una sociedad patriarcal:

-Creo, continuó doña Maria, que vosotros hariais bien en casar á Gabriela con Juan. Es el modo mas simple de reunir bajo un mismo nombre toda nuestra fortuna. Gabriel puede ser el tutor de su yerno, la muchacha, tal vez repugne, pero eso no viene al caso; en mi tiempo no se consultaban caprichos de muñecas, yo me casé sin querer á mi marido, lo conocí el dia que fuimos á la Iglesia; despues demas de dos años es que me resolví á levantar los ojos para mirarlo, pues no lo hallé ni feo ni bonito, antes le tenia rabia que no amor. Ni creo que el amor sea necesario para casarse, iqué amor ni qué sonsera! ("La familia del comendador: Nuera y Suegra" en Álbum de Señoritas 5 (29/1/1854) 37, subrayado mío).

Como lo planteáramos más arriba, toda sociedad organizada bajo presupuestos patriarcales se consolida a partir de una figura paterna, la que al mantener y conservar el poder absoluto sobre los miembros de la casa, actualiza una modalidad que puede ser fácilmente homologada a algunos sistemas de esclavitud. Esto es precisamente lo que dice Juana Manso en su periódico: lo dice a través de las modulaciones de un relato de ficción y en tono novelado como modo de narrar. En este contexto, una forma cultural como la novela es considerada de suma importancia en la formación de los imaginarios simbólicos de los modos sociales a través de los cuales - y finalmente - se inscriben (y se escriben) las naciones. No digo que sólo la novela sea importante sino que la considero como el objeto estético cuya conexión con esas sociedades (naciones) en formación es particularmente interesante de estudiar desde su emergencia como práctica simbólica. Esta afirmación parte, obviamente, de considerar a la (forma)novela en sentido extendido, es 
decir, como esa forma cultural que funda actitudes, referencias y experiencias en el imaginario de una época al mismo tiempo que realiza el gesto de decirlo. Desde su(s) trama(s) narrativa(s) organiza el espacio de la historia modalizándola como ficción, bloqueando otras narraciones emergentes o en formación.

Como un crítico ha sugerido, las naciones en sí misma son narraciones y como decíamos hace un momento, el poder de narrar, o de bloquear otras narrativas en formación o en emergencia, es muy importante para la relación entre cultura/nación dado que constituye una de las principales conexiones entre ambas. En este sentido cultura sería esa suerte de teatro donde varias causas políticas e ideológicas se comprometen entre sí. Lejos de ser un plácido dominio de una amable convivencia, la cultura puede ser hasta un campo de batalla donde las causas se exponen a sí mismas a la luz del día mientras compiten unas con otras.

Sabedora de estar encabezando un espacio combativo en ese campo de batalla, Juana Manso de Noronha señala con el dedo los lugares que han sido invadidos por el silencio y los descubre sin compasión. Al homologar la esclavitud con la situación real de la mujer en una sociedad patriarcal debe haberse enfrentado con el desagrado explícito de sus lectoras. No contenta, sin embargo, con la homologación ficcionalizada decide "rematar" - tanto en sentido literal cuanto en el metafórico — su planteo, por lo que "suspende" el relato hasta la próxima entrega - con el siguiente planteo:

Despues, la abuela se dirigió á Gabriela, haciéndole mil elogios, enumerando un largo catálogo de lo que le tocaba en suerte, sobre alhajas, esclavos \&a. \&a. y el párrafo final fué el anuncio de su casamiento con su tio D. Juan el loco!

A ese anuncio fatal Gabriela se puso en pié, abrió los ojos espantada, se puso pálida como la muerte, y despues de un momento de silencio en que su cuerpo temblaba, como el vástago de una tierna planta sacudido por el huracan, dijo con voz firme:

- "Antes seré monja que casarme con mi tio".

Muchas reflecciones se le hicieron, y muy brillantes fueron las promesas.

Gabriela oyó todo en silencio. Como todos los caracteres resueltos, usaba pocas palabras. Creia que habia contestado y reunia sus fuerzas para la lucha ("La familia del comendador: Nuera y Suegra" en Álbum de Señoritas 5 (29/1/1854) 38, subrayado mío).

En este capítulo de La familia ... aparece una de las tantas modalidades sonoras que puede "entonar" el silencio: la del claustro, es decir, la del encierro como única "salida para un caracter resuelto que utiliza pocas palabras y reúne sus fuerzas para la lucha". En este contexto, la denuncia ficcional de la narradora nos conduce a confirmar que el silencio a menudo, se sostiene como única respuesta cuando ese otro se ve sumida en un modelo de legitimaciones que no le pertenecen. ${ }^{24}$

${ }^{24}$ Desde una militancia de vida narrativa Angélica Gorodischer “aclara" esta afirmación cuando dice: "Lo voy a repetir no sea que nos lo olvidemos: la marca del género mujer es la exclusión. Exclusión del poder, exclusión de la palabra. El lenguaje es parte del poder político y de la ideología de los que mandan que, innecesario me parece decirlo, no somos nosotras a pesar del treinta por ciento y de alguna primera ministra, regenta, emperatriz o presidenta. Quitarnos la voz es reducirnos a cuerpos silenciosos, que son tan cómodos" (Area, Pérez y Rogieri 175-182). 
Sin embargo, se puede elegir no hacer silencio, es decir, no (a)callar resignadamente la propia voz, sabiendo - eso sí- que dicha elección implica salirse de madre -o tal vez, para ser más justos, deberíamos decir salirse de los bordes fronterizos que el paternalismo -que ejerce el control simbólico en una sociedad - traza como márgenes insalvables para todo aquél(la) que quiera ser "reconocido/a" dentro del grupo ${ }^{25}$ protector. Con Juana Manso es fácil observar cómo ella decide atravesar esos bordes sonoramente; sonido que va in crescendo a medida que saltamos de un artículo a otro, es decir, de un tema a otro; sonido que hasta, en alguno casos, se vuelve ensordecedor y nos renueva el recuerdo de aquel (casi) ruego que le dirigiría Sarmiento: "Baje U., pues la voz en sus discursos y en sus escritos a fin de que no llegue hasta aquí el sordo rumor de la displicente turba" (Nueva York, 1867) (Zuccotti en Fletcher, Mujeres y cultura 107). Pretensión inútil en lo que a esa mujer se refiere ...

En "Las Misiones", nota que sigue a continuación, somos espectadores de un salto a un metafórico vacío en la pluma de alguien que pretende decir lo que no se debe - y tanto peor si ese alguien, además, viste polleras y escribe. El tópico tratado en este artículo asume el tono de la denuncia a través de la cual se puede inferir que el proyecto político que, en ese año de 1854, impulsaba la construcción de una nueva nación adolecía de parecidas injusticias de las que tan acerbamente se le habían criticado a Rosas. Recordemos, por ejemplo, una de las tantas acusaciones dirigidas al Restaurador de las Leyes, esta vez en la pluma de Esteban Echeverría, cuando en la polémica que sostuviera con Pedro de Angelis - a propósito de los ataques de éste al Dogma Socialista, credo y programa de la Generación del 37- el escritor replicaba:

Estais oprimiendo, profanando, barbarizando vuestra tierra, la estais convirtiendo en una toldería donde no se reconoce más ley que la fuerza, más razón que el instinto o el capricho bruto, más pena que la confiscación o el degüello (Echeverría 251).

En un tono similar, pero esta vez ya no dirigido al gobierno de Rosas sino a los representantes del proyecto "civilizador", Juana Manso muestra su preocupación frente a una inminente campaña contra los indios: "va á correr la sangre de nuevo" — nos dice, mientras articula un cuestionamiento político- “¿Será que no haya otros medios de persuasión para esos desventurados, sino el sable y el plomo?” El interrogante abre mucho más que el espacio de una pregunta retórica ya que el estado de beligerancia permanente en que se había visto inmersa la región del Río de la Plata en los pasados treinta años había sido lo suficientemente doloroso como para ser olvidado. Sin embargo, Manso realiza una nueva torsión en su apelación hasta llevarla al corazón de la denuncia y, es entonces cuando ya no quedan dudas sobre el hecho de que la periodista ha cruzado ciertos márgenes con respecto a lo que estaba permitido/no permitido decir a una mujer en su época. Al trasponer con enorme valentía esos márgenes, hace que su palabra se muestre investida de una voz que lleva sobre sí todas las marcas de la marginación que sufrirá en poco tiempo. Asaltando

25 "Conté siempre con obtener la protección de la clase ilustrada y del círculo abastado de Buenos Aires .... Nada he conseguido!" se lamentará mientras acusa Juana Manso en la nota "A Nuestras Subscriptoras" de esta misma entrega. 
el espacio público, la cronista toca con su pluma zonas discursivas que han permanecido insistentemente "átonas" a lo largo de la historia patria y dice:

Sí, creemos (...) que esta expedicion armada debe ser la última que parte contra los indios. El fanatismo ha muerto, no es posible resucitarlo; el espíritu verdadero del cristianismo resplandece sobre todas las quimeras, ambiciones y combinaciones humanas, el impulso está dado y no es posible retroceder.

Padres de la Iglesia que llevais el nombre de cristianos, cumplid el precepto del Evangelio Id y predicad diciendo que se acercó el reino de los cielos.

No poseais oro ni plata, ni dinero en vuestras fajas.

No alforja para el camino, ni dos túnicas, ni calzado, ni baston; porque digno es el trabajador de su alimento.

Evangelio segun San Mateo

Sí, reunios que no os faltará proteccion y partid para la pampa. En vuestro tránsito encontrareis cristianos que solo llevan este nombre, cuya alma está seca y descreida, de cuyos ojos no acostumbra correr ni una sola lágrima de piedad, á esos tambien es necesario acudir.

Con todo, ved que no os pido que váyais á fanatizarlos, no á lanzar anatemas, y á pavorizarlos con el infierno.

Habladles de caridad, de fé de esperanza, de la misericordia divina; ceñid vuestras palabras al espíritu puro y luminoso de la doctrina del divino maestro.

De todos los materialismo, el de la religion es el mas funesto ... ("Las Misiones" en Álbum de Señoritas 5 (29/1/1854) 38, subrayado en el original).

Llegados a este punto no podemos dejar de reconocer que, en su osada empresa, el Álbum de Señoritas era una apuesta intelectual demasiado lúcid $a^{26}$ para un 1854 conflictivo

\footnotetext{
${ }^{26}$ Quince años más tarde, una evaluación de asombrosa similitud será la de Lucio V. Mansilla otro lúcido marginal cuya escritura curiosamente adoptara modalidades femeninas - en su Una excursión a los indios ranqueles donde se manifiesta en oposición al exterminio (“... todos los americanos tenemos sangre de indio en la venas, ¿por qué ese grito constante de exterminio contra los bárbaros?" [Mansilla 392]), mientras se pronuncia por una política de integración pacífica (“¿Cuál es el remedio que costando menos sangre puede conciliar el hecho con el derecho? ... mientras para todo ... presentéis el filo de una espada, la clemencia humana estará en su derecho de exclamar: ¡Fratricidas!" [Mansilla 251]) y plantea la obligación - como cristianos y argentinos-de crear las condiciones para la convivencia ("¿Qué más podían hacer aquellos bárbaros sino lo que hacían? ¿Les hemos enseñado algo nosotros que revela la disposición generosa, humanitaria, cristiana de los gobiernos que rigen los destinos sociales? Nos roban, nos cautivan, nos incendian las poblaciones, es cierto. ¿Pero qué han de hacer si no tienen el hábito del trabajo? /.../ ¿A quién la culpa, sino a nosotros mismos?" [Mansilla 137]; "Tanto que declamamos sobre nuestra sabiduría, tanto que leemos y estudiamos, ¿y por qué/Para despreciar al pobre indio, llamándole bárbaro, salvaje; para pedir su exterminio, porque su sangre, su raza, sus instintos, sus aptitudes, no son susceptibles de asimilarse a nuestra civilización empírica, que se dice humanitaria, recta y justiciera, aunque hace morir a hierro al que a hierro mata, y se ensangrienta por cuestiones de amor propio, de avaricia, de engrandecimiento, de orgullo ..." [Mansilla 373]). (La siguiente selección de citas junto al planteo sobre Lucio V. Mansilla me fue sugerida por el trabajo de Cristina Parodi en Area, Fogsgaard y Parodi 42.
} 
y en construcción. Asimismo, es fácil percibir el profundo "desagrado" que planteos como los anteriormente expuestos deben haber provocado en los integrantes de la gran aldea porteña post-Caseros dado que todos conocían el hecho de que cosas como ésas no podían decirse, menos escribirse y menos aun aparecer ante los ojos de un público lector femenino quien no debía ser turbado ni por la duda ni por el cuestionamiento sobre las decisiones político-institucionales que los líderes de la fundación nacional (padres, esposos, hijos, hermanos) estaban llevando a cabo. Más aún, en el espacio del hogar se imponía la calma para esos hombres a la hora de tomar las decisiones y esa calma sólo sería provista si los lugares públicos y privados - por ellos sancionados - sostenían las valoraciones que se les asignaban (bueno/malo; permitido/prohibido). ¿Qué hacer, entonces, frente a la posibilidad de que madres, esposas, hijas o hermanas pudiesen llegar a ser con-movidas por reflexiones del tipo de la que a continuación transcribimos?

La experiencia nos ha demostrado que el indio tiene inteligencia, y cuando civilizado, hemos visto desenvolverse en ellos mil sentimientos nobles y generosos, mil tendencias que muestras que su corazon solo está pervertido por la ignorancia: tendamos, pues, la mano á esos desgraciados para sacarlos de la densa noche que los envuelve.

Esta patria es de ellos como nuestra. La conquista los esclavizó, los arrojó de sus lares los despedazó, y nosotros despues de la independencia no hemos hecho mas que continuar la obra que comenzó la conquista. Para atraerlos á nuestra amistad no hemos tenido otros arbitrios que, ó subyugarlos con el hierro mortífero, ó halagarles su vanidad con zarandajas, orígen de discordia entre ellos, ó licores perniciosos con que hemos acabado de viciarlos.

Buenos Aires empieza una era nueva; es necesario que todo elemento de progreso entre en el cuadro de su nueva marcha ("Las Misiones" en Album de Señoritas 5 (29/1/1854) 39 , subrayado mío).

¿Qué hacer frente a la insolencia de esa mujer que se atrevía a señalar, criticar y hasta invalidar espacios públicos tradicionalmente sacralizados tales como el proyecto político para un Estado en fundación, la Iglesia católica, el lugar subsidiario - y servil- de la mujer en la sociedad? ¿Qué hacer, además, con una mujer que era fea, pobre, abandonada por su marido? La historia como relato nos ha mostrado que la respuesta a parecidos interrogantes ha sido siempre coherentemente homogénea: la reacción que provoca el diferente, en una sociedad, asume las modalidades del descrédito, la indiferencia cuando no actitudes mucho más violentas que tienen como objetivo y finalidad el (a)callar toda voz que pretenda desacomodar un orden ${ }^{27}$ establecido.

En el caso Juana Manso, la respuesta de la sociedad porteña no sólo fue el descrédito (el que si bien apela a la devaluación de la palabra ajena por lo menos permite ciertas instancias de defensa (parcial) por parte del desacreditado) también —y con mucha más fuerza - fue el rencoroso y displicente mutismo que vacía al otro de toda posibilidad sonora mientras lo ubica en el doloroso registro de la inutilidad de su palabra. Y digo mutismo y no silencio, precisamente, porque considero que existen diferencias entre ambas

\footnotetext{
${ }^{27}$ Y recordemos que ... - como lo señalara alguna vez Roland Barthes— orden no sólo significa organización, también implica conminación.
} 
sonoridades; el mutismo tendría mucho más que ver con una decisión personal mientras que el silencio implica que la presión la ejerce el otro, ${ }^{28}$ siempre desde un lugar de poder institucional.

Silenciar a Juana Manso fue una tarea imposible a lo largo de su altisonante y luchadora existencia, sin embargo sí fue posible responderle con extrema violencia y que cada una de esas respuestas significaran ejercer sobre ella diversas modalidades de silenciamiento, ${ }^{29}$ todas ellas verdaderamente feroces. La falta de suscriptoras, en lo referente al Álbum de Señoritas, sería el modo adoptado en esta ocasión; falta que no sólo implicaba (de)mostrarle a la redactora la inutilidad de su palabra inteligente sino que, al mismo tiempo, ubicaba a la mujer en la precariedad y desamparo económicos al condenarla a un trabajo sin retribución.

La quinta entrega del periódico continúa, tras "Las Misiones", con el relato de una pequeña anécdota ${ }^{30}$ para seguir con otra nota que es una dura respuesta "Al Señor G. de la "Tribuna'" donde la periodista defiende su mirada crítica con respecto a lo que debía considerarse un artista; se defiende y se desborda como si la presión ejercida sobre ella por las palabras del "Señor G." hubiesen abierto una compuerta verborrágica difícil de contener. Manso se enoja, polemiza, grita, alza la voz, tal vez, porque sabe que escasamente será escuchada mientras se atreve a enrostrale al crítico de la "Tribuna" que:

He defendido el nombre de artista contra el ridículo que se quería lanzar sobre él, porque era un deber mío no solo como muger de un artista, sino porque es odioso dejar profanar aquello que merece respeto.

Si yo fuese estúpida creeria que mi marido es el único artista que existe. Felizmente no lo soy y tengo nociones mas claras que el Sr. G. de lo que es arte para cometer error tan craso.

He llamado á Robbio de charlatan, porque lo es, y como él, hay centenares de tocadores, á quienes no es permitido equivocarlos con un Sivori, con un Viemtemps \&a. \&a., ni con

\footnotetext{
${ }^{28}$ Pensemos en todo el paradigma asociativo que la palabra silencio convoca y observaremos que la acción de silenciar es direccional y jerárquica pudiéndose dibujar coordenadas discursivas que van de arriba hacia abajo y de afuera hacia adentro. Por ejemplo: silenciar, silenciador, silenciamiento. ${ }^{29}$ Sólo a título de confirmación emblemática de lo que vengo exponiendo, considero interesante citar aquí mi coincidencia con Liliana Zuccotti en su trabajo sobre "Las conferencias de maestras" cuando afirma que las "reacciones que generara son de una violencia y una irritación inéditas. En su tercera conferencia en Chivilcoy, organizada con el objeto de juntar fondos para construir una biblioteca, cuando comenzaba a leer su drama 'Rosas', apedrean la escuela a cascotazos, y al salir, le lanzan asafétida en la ropa. Antes de comenzar una conferencia sobre 'La reforma religiosa en Europa', en la escuela de Catedral al Norte, recibe una carta en la que se le suplica silencio sobre materias religiosas, amenazándola con la aparición de un sacerdote para coartarle la palabra y delatarla al Obispo por hereje. Un 'populacho grosero' (cuenta en los Anales de la educación común, 1867) se apiñaba en las ventanas del salón en que estaba hablando para gritar obscenidades a las damas que acudian a las conferencias" (Zuccotti en Fletcher, Mujer y cultura 103, subrayado mío).

${ }^{30}$ Tierna y descontextualizada "Coincidencia singular" relata la presencia de una paloma blanca en dos momentos de la "augusta" existencia de la princesa Da. Maria da Gloria, despues reina de Portugal. El día que fuera bautizada y el día de su muerte. Pareciera como si Juana Manso sólo podía "tocar" temas entrañables cuando su recuerdo "volaba" a lugares-otros.
} 
otros que se respeten á sí mismos, lo bastante para no prostituir el arte al oficio de pallazos. Sino fuí modesta en callarme, y curvar mi frente ante los fallos augustos de la clasificacion artística del Sr. G. lo siento mucho, y doy los parabienes al Sr. G. si él sabe ser tan inteligente como modesto. Sus obras lo dicen mejor que podría hacerlo yo ("Al Señor G. de la "Tribuna" en Álbum de Señoritas 5 (29/1/1854) 39-40, subrayado original).

Tal vez - y precisamente - por todo lo anteriormente expuesto es que "A Nuestras Subscriptoras" se vuelva la marca privilegiada para evaluar el proyecto periodístico del Álbum de Señoritas y su frustración. Con una mirada responsable y profesional que habla, también, del lugar de soledad que toda decisión implica, J. P. M. de Noronha -como firma la nota-, hace el balance parcial de su empresa (podríamos decir, tanto en sentido literal cuanto en el metafórico):

Hemos llegado al $5^{\circ}$ y último número del Album en este primer mes de su existencia. Ningun sacrificio he ahorrado para darle vida y consistencia. Toda mi ambicion era fundar un periodico dedicado enteramente á las señoras, y cuya unica mision fuese ilustrar; lo habia conseguido asi en el Rio Janeiro donde «El Jornal das Senhoras» está en el tercer año de su publicación. Las simpatias que merecí en aquella corte, los testimonios todos de deferencia y de apoyo, con que me favorecieron, me indugeron á esperar otro tanto en mi pais ... Infelizmente mis esperanzas fueron flores pasageras, que el viento del desengaño deshojó al querer abrir ... (“A Nuestras Subscriptoras” en Álbum de Señoritas 5 (29/1/ 1854) 40).

Un balance que podría ocupar varias columnas de un libro "doméstico" de gastos diarios cuyos deber y haber descubrirían los costos reales y simbólicos de una empresa que se resiste a adocenadarse pero que, al mismo tiempo, se resiente en su falta de apoyo. Juana Manso apela al corazón de "sus queridas subscriptoras" instalando la palabra de una mujer que habla a otras: "antes que escritora yo soy madre de familia, es este un cargo que trae inmensa responsabilidad, y que me impone deberes muy sérios! ..." "Mi ambición no es la plata", dirá, "No tengo fortuna pero tampoco abrigo deseos dispendiosos. Tengo fé en la Providencia y cuando me inquieto no es personalmente por mí, y sí por aquellos á quienes soy necesaria".

El deber y el haber arman dos escenarios para la evaluación de un mismo proyecto. Por una parte, la trayectoria de Manso en Brasil, el éxito de su O Jornal das Senhoras, el claro objetivo intelectual (y también político) del Álbum son los antecedentes públicos de una mujer comprometida no sólo con su época sino con el espacio geo-político en que le había tocado nacer y al cual había elegido retornar. Pero, al mismo tiempo, la Manso es una mujer que lleva sobre sus hombros el "mandato" cultural de la responsabilidad materna, tarea privada e inalienable. Lo insoportable en ella será, entonces, el hecho de que haya intentado ocupar ambos espacios sin tener ninguno de los respaldos tradicionales a sus espaldas: dinero, belleza, familia, nombre o marido. Era insoportable tanto para los hombres como para las mujeres del Buenos Aires post-rosista porque sus pretensiones la mostraban carente y solvente, a la vez. Carente, solvente e insolente dado que no tenía reparos en exponer tanto sus créditos como sus réditos sin maquillaje alguno: 
Con todo, si puedo conformarme con no ganar, y si nunca he considerado la fundacion de este periódico como un medio de especulacion, tampoco ha podido nunca entrar en mis cálculos de presupuesto mensual y de economía doméstica, gastar una fuerte suma por mes en imprimir papel cuyo destino mas próximo será ir para alguna taberna á envolver azúcar y arroz.

Conté siempre con obtener la proteccion de la clase ilustrada y del circulo abastado de Buenos Aires.... Nada he conseguido!

Con todo, haré el sacrifico un mes mas, y si en este tiempo no se reuniese una subscripcion suficiente á cubrir los gastos de la publicacion, no tendré otro remedio que despedirme de mis lectoras, agradeciéndoles su proteccion y deseando que otra mas feliz que yo sea mejor sucedida.

J. P. M. de Noronha

(“A Nuestras Subscriptoras" en Álbum de Señoritas, 5, 40).

Dos breves notas cierran esta quinta entrega; la referida al tema de "Modas" y otra denominada "Máximas Morales" que despliega una serie de enunciados ejemplares, todos ellos sentenciando acerca de la adversidad y la desposesión. ${ }^{31}$ Sin embargo este número del periódico no termina aquí sino que tras las notas arriba mencionadas aparecen dos avisos altamente significativos en la medida en que ambos completan y cierran el balance realizado por la redactora-mujer. Este cierre, tomado como dato "al margen" - que apunta directamente a la centralidad del problema - tiene la claridad de informarnos acerca de la ubicación (tanto pública cuanto privada) que la fallida empresa de edición del periódico le había destinado a Juana Manso a fines de ese enero de 1854. Dos avisos, entonces, que se sostienen en los diversos presupuestos y sobreentendidos que hemos intentado explicitar a lo largo de nuestro análisis. Así, ellos "anuncian" que:

Graves ocupaciones, nos impiden publicar la crónica de la quincena. Desde el próximo número, publicaremos una crónica semanal.

Para el próximo mes de Febrero, la redactora del Album, ofrece dar lecciones de los idiomas, inglés, francés é italiano, en casas particulares (Álbum de Señoritas 5, (29/1) 1854) 40).

Es tan cierto que Juana Manso carecía de esa "capacidad" de disimulo que, ya sea en sentido amplio como en el restringido, brinda el maquillaje $\mathrm{e}^{32}$ que no tiene reparos en

${ }^{31}$ La prosperidad grangea amigos. La adversidad los prueba.

Errar es humano. Perdonar es divino.

Áquel que se contente con lo que posee, será siempre el mas rico.

Nunca granjeará un amigo verdadero, aquel que cambia de amistades con frecuencia.

No hay victoria mas gloriosa sobre los otros, que volver el bien por el mal. El corazon de los locos está en su boca, pero la lengua de los sábios, está en su corazón.

"Máximas Morales" en Álbum de Señoritas 5, (29/1/1854) 40.

${ }^{32}$ Dijo alguna vez el sagaz Sarmiento algo con respecto a la Manso que no puedo menos que evocar aquí en función de que su lúcida evaluación confirma lo por mí planteado: "Existe en Buenos Aires una institución para honrar a las mujeres. ¿Por qué no está la Manso en su seno? Porque es ocre". Véase Domingo F. Sarmiento, $O C$., Tomo 29, p. 109. Citado por Liliana Zuccotti, en Fletcher, Mujer y cultura 107. 
descubrir - ante los ojos de sus lectoras - su digna precariedad; dignidad que sostiene en una apuesta coherente con la profesionalización de la mujer. Manso no ruega, tampoco suplica sino que al finalizar el primer mes de edición expone el estado de situación de su proyecto. Sabe que sin apoyo, el mismo se frustrará; propone, entonces, "el sacrificio de un mes mas" pero mientras tanto, ofrece - se ofrece desde - sus servicios apostando a lo que la constituye como profesional: instruir, ilustrar, es decir, educar. En toda ocasión su apuesta había sido ejemplar: volver a la tierra natal para consagrar todos sus esfuerzos a la ilustración de sus compatriotas, su tono también lo era y no menos habrá de ser su frustración; cada uno de esos estadios prefiguran los modos de leer que Juana Manso pondrá en escena para narrar el diseño y fundación de una nación en conflicto desde sus márgenes y a lo largo de su vida de intelectual comprometida. Márgenes que, en su caso y en forma emblemática, la destinaran a la permanente lucha contra el mandato y la resignación de bajar la voz.

\section{Bibliografía}

Anderson, Bendict. Imagined Communities: Reflections on the Origin and Spread of Nationalism. London: Verso, 1983.

Angenot, Marc. 1889. Un état du discours social. Montréal: Éditions du Préambule, 1989.

Area, Lelia. "Pedro de Àngelis: mirada y voz de un tercero". AA. VV. Reflexiones sobre el V Centenario. Rosario: Editora UNR-Facultad de Humanidades y Artes, 1992 (también en Revista Anales 3. Suecia: Instituto Ibero-americano, Universidad de Gotemburgo, 1993.

, Lene Fogsgaard y Cristina Parodi. Sarmiento, Mansilla, Hernández, Güiraldes: modos de escribir la Argentina. ISA 54. Romansk Institut, Aarhus Universitet, 1993.

y Mabel Moraña (Eds.). La imaginación histórica en el siglo XIX. Rosario: UNR Editora, 1994.

, L. Pérez y P. Rogieri. "Cómo enfermarse de la garganta". Fin de un siglo: las

fronteras de la cultura. Rosario: Homo Sapiens Ediciones, 1996. 175-182.

Barthes, Roland. Fragmentos de un discurso amoroso. Madrid: Siglo XIX, 1986.

De Certeau, Michel. La escritura de la historia. México: Universidad Iberoamericana, Departamento de Historia, 1993.

Echeverría, Esteban. "Defensa del Dogma". El Dogma Socialista. Buenos Aires: Ediciones del Plata, 1940. 251.

Fletcher, Lea. "Patriarchy, Medicine, and Women Writers in Nineteenth-CenturyArgentina". B. Clarke y W. Aycock (eds.). The Body and the Text. Comparative Essays in Literature and Medicine. Lubbock, Texas: Texas Tech University Press, 1990.

(Ed.). Mujeres y cultura en la Argentina del siglo XIX. Buenos Aires: Feminaria Editora, 1994.

"Juana Manso: una voz en el desierto". Mujeres y cultura en la Argentina del siglo XIX. Lea Fletcher, ed. Buenos Aires: Feminaria Editora, 1994. 
Gregory, Derek. Geographical Imaginations. Cambridge, MA y Oxford, UK: Blackwell, 1994.

Jiménez, Sergio y Edgar Ceballos (comps.). "Una polémica sobre dirección". Técnicas y teorías de la dirección escénica. México: Col. Escenología-Grupo Gaceta, 1988.

López García, Ángel y Ricardo Morant. Gramática femenina. Madrid: Cátedra, 1991.

Manso de Noronha, J. O Jornal das Senhoras, Modas, Litteratura, Bellas-Artes, theatros e Critica., Tomo 1 y Tomo 2, (1 de Janeiro de 1852 a 4 de Juhlo de 1852), Material microfilmado, Biblioteca Nacional de la Ciudad de Rio de Janeiro, Brasil. Álbum de Señoritas, periódico cultural, 8 entregas, $\left(1^{\circ}\right.$ de enero a 17 de febrero de 1854), Sala del Tesoro, Biblioteca Nacional Argentina, Buenos Aires.

Mansilla, Lucio. Una excursión a los indios ranqueles [1870]. México, Buenos Aires: Fondo de Cultura Económica, 1947.

Masiello, Francine. Between Civilization and Barbarism. Women, Nation and Literary Culture in Modern Argentina. Lincoln \& London: University of Nebraska Press, 1992.

(comp.). La mujer y el espacio público. El periodismo femenino en la Argentina del siglo XIX. Buenos Aires: Feminaria Editora, 1994.

Rivera, Jorge. Antologia de la novela popular. Buenos Aires: Biblioteca Básica Universal, CEDAL, 1971.

Stanislavski, Constantin. Preparación del actor. Traducción del francés de Ricardo Debenedetti. Buenos Aires: Leviatán, 1960. 263.

Stratta, Isabel. "Viajeros intertextuales". La imaginación histórica en el siglo XIX. Lelia Area y Mabel Moraña, eds. Rosario: UNR Editora, 1994.

Velasco y Arias, M. Juana Paula Manso. Vida y Acción. Buenos Aires: Talleres Gráficos Porter Hnos, 1937.

Viñas, David. Literatura argentina y realidad politica. Buenos Aires: Jorge Alvarez Editor, 1964.

Literatura argentina y realidad política. De Sarmiento a Cortázar. Buenos Aires: Siglo Veinte, 1974.

Zuccotti, Liliana. "Gorriti, Manso: de las Veladas literarias a 'Las conferencias de maestra"". Mujeres y cultura en la Argentina del siglo XIX. Lea Fletcher, ed. Buenos Aires: Feminaria Editora, 1994. 
